\title{
TEORES DE CARBOIDRATOS EM ÓRGÃOS LENHOSOS DO CAQUIZEIRO EM CLIMA TROPICAL ${ }^{1}$
}

\author{
CARLOS EDUARDOCORSATO², JOÃO ALEXIO SCARPARE FILHO ${ }^{3}$, ELEUZACLARETE JUNQUEIRADE SALES $^{4}$
}

RESUMO-Nas fruteiras caducifólias, o metabolismo de carboidratos constitui-se no principal mecanismo que garante a sua sobrevivência no período de dormência, estando, também, relacionado ao seu potencial produtivo em safras subseqüentes. Conhecer a forma como a planta utiliza esses carboidratos durante o seu desenvolvimento é um passo importante para o entendimento das suas relações fonte-dreno e para fundamentar algumas práticas de manejo, como a poda e o raleio de frutos. Caracterizar a variação dos teores de amido e de carboidratos solúveis totais em órgãos lenhosos do caquizeiro (Diospyros kaki L.), no decorrer do seu desenvolvimento fenológico, foi o objeto de investigação do presente estudo. O trabalho foi conduzido em um pomar de caquizeiros localizado na área experimental da Escola Superior de Agricultura "Luiz de Queiroz" (ESALQ), em Piracicaba, Estado de São Paulo, durante o ciclo 2002/ 2003. A fenologia das plantas foi caracterizada pelo período de ocorrência e duração do alongamento dos ramos, florescimento, desenvolvimento dos frutos e das folhas e do abortamento natural de frutos. A variação dos teores desses carboidratos em ramos e em raízes foi analisada tendo por base os diferentes estádios fenológicos. Ocorreram variações significativas no teor desses carboidratos no período de estudo. A mobilização do amido nos ramos teve grande importância na sustentação de um novo ciclo de brotações. O maior consumo de amido ocorreu durante a abscisão foliar, e a reposição no seu estoque, nos ramos e nas raízes ocorreu, principalmente, entre o florescimento e a abscisão foliar.

Termos para indexação: fenologia, desenvolvimento, amido.

\section{CARBOHYDRATE CONTENT IN PERSIMMON TREE WOODY ORGANS IN TROPICAL CLIMATE}

\begin{abstract}
In deciduous fruit trees, the carbohydrate's metabolism are recognized as the main mechanism that ensures their survival during the rest period. Besides it, the very same metabolism is related to the productive potential in subsequent harvest seasons. Knowing how the plants use those carbohydrates during their development and growth is an important step in the right direction to understand the relation source-drain more effectively along with building up the fundamentals of some handling practices, for instance, the pruning and fruit thinning. The objective of the present study was to characterize how the total soluble sugars content and the starch vary in woody organs of the persimmon tree (Diospyros kaki $\mathrm{L}$ ) in elapsing of its phenological development. This study was carried out in the experimental area of the Escola Superior de Agricultura "Luiz de Queiroz" (ESALQ) in Piracicaba - SP, during the cycle 2002/2003. The phenology of persimmon tree was described by the occurrence period and prolongation of shoot growth, flowering, fruit growth, leaf expansion and natural abortion of fruits. The carbohydrates content in stems and roots were analyzed based on different phenological stages. The results showed a significant variation in the starch and total soluble sugars content in the sampled organs. The starch's mobilization in stems was of foremost importance to sustain the beginning of a new growing cycle. It is worth mentioning that the consumption of starch was increased during the leaf fall and therefore a replacement in its stock took place, not only in the stems but also in the roots, during the flowering and the leaf abscission.
\end{abstract}

Index terms: phenology, development, starch.

\section{INTRODUÇÃO}

Pertencente à família das ebenáceas, o gênero Diospyros agrega predominantemente espécies sempre verdes, encontradas em climas subtropicais. No entanto, um pequeno número de espécies adaptou-se ao clima temperado, dando origem a algumas espécies de hábito decíduo (Mowat et al.,1995), dentre as quais a de maior valor comercial é o caquizeiro (Diospyros kaki). Sua introdução no Brasil ocorreu no final do século XIX; no entanto, a expansão da cultura no País só ocorreu em 1920 com a chegada de imigrantes japoneses que trouxeram outras variedades e o domínio da produção. Hoje, no Brasil, a participação dos principais estados produtores de caqui está concentrada nas regiões Sul e Sudeste, sendo responsáveis, respectivamente, por $30 \%$ e $65 \%$ da produção brasileira (Sato \&Assumpção, 2002).

O caquizeiro é uma espécie lenhosa que apresenta alternância entre períodos de crescimento e dormência, de acordo com a sazonalidade climática nas diferentes regiões onde é cultivada (Mowat \& George, 1994). Na estação de crescimento,

1(Trabalho 118-07). Recebido em: 07-05-2007. Aceito para publicação em: 21-11-2007.

${ }^{2}$ Engenheiro Agrônomo, Dr., Professor do Departamento de Ciências Agrárias da Universidade Estadual de Montes Claros, Rua Reinaldo Viana, ${ }^{\circ}{ }^{2630}$, CEP 39440-000, C.P. 91, Janaúba - MG, (038) 3821-2756, carlos.corsato@unimontes.br.

${ }^{3}$ Engenheiro Agrônomo, Dr., Professor do Departamento de Produção Vegetal, Setor de Horticultura, Escola Superior de Agricultura "Luiz de Queiroz" -USP, Av. Pádua Dias 11, 13418-900, Piracicaba-SP, (019) 3429-4100, jascarpa@esalq.usp.br.

${ }^{4}$ Zootecnista, Dra., Professora do Departamento de Ciências Agrárias da Universidade Estadual de Montes Claros, Rua Reinaldo Viana, ${ }^{\circ}$ 2630, CEP 39440-000, C.P. 91, Janaúba - MG, (038) 3821-2756 eleuza.sales@unimontes.br.

Rev. Bras. Frutic., Jaboticabal - SP, v. 30, n. 2, p. 414-418, Junho 2008 
ocorre o alongamento das brotações e a expansão foliar, cujo desenvolvimento se completa pouco antes do florescimento (Mowat \& George, 1994). Durante o período de atividade fotossintética, o eventual excedente em compostos fotoassimilados produzidos pela planta fica imobilizado na forma de carboidratos insolúveis em órgãos aéreos e subterrâneos da planta, sendo, então, mobilizados gradativamente em carboidratos solúveis durante o período de dormência. Com o fim da dormência, essa mobilização é acelerada, sendo os carboidratos solúveis conduzidos para as gemas em brotação que, por sua vez, formarão novos ramos e folhas; posteriormente, as flores e os frutos são supridos, seguidos pelo câmbio, por novas gemas em formação e, finalmente, pelos tecidos que servem como depósito de carboidratos em órgãos subterrâneos e aéreos da planta (Wardlaw, 1990; Larcher, 2000). O amido é o principal carboidrato de reserva do caquizeiro, sendo facilmente mobilizado para formas solúveis durante o seu desenvolvimento (Mowat \& George, 1994).

A época da mobilização dos carboidratos presentes nos órgão lenhosos da planta está diretamente ligada aos eventos climáticos, sobretudo à temperatura, tendo grande importância nos estudos de adaptação de frutíferas de clima temperado (Herter et al., 2001). A intensidade dessa mobilização influencia, por sua vez, no desenvolvimento fenológico da planta, como no crescimento de ramos, no florescimento e na produção de frutos (Liu et al., 1999; Larcher, 2000). As variações dos teores de carboidratos em órgãos vegetais têm sido estudadas em diversas espécies cultivadas, como em nogueira pecã (Smith et al., 1986), mirtilo (Darnell \& Birkhold, 1996), abacateiro (Liu et al., 1999), macieira (Carvalho \& Zanette, 2004), em espécies forrageiras (Vantini et al., 2005), em pereira (Rodrigues et al., 2002), entre outras. Nas regiões de clima tropical, sobretudo nas condições do Brasil, estudos sobre o desenvolvimento fenológico do caquizeiro cultivado (Corsato et al., 2005) e sua relação com a variação dos teores de carboidratos na planta são praticamente inexistentes.

O objetivo deste trabalho foi analisar a variação dos teores de amido e de carboidratos solúveis totais em raízes e ramos do caquizeiro no decorrer de um ciclo de desenvolvimento.

\section{MATERIAL E MÉTODOS}

A área experimental consistiu num pomar de caquizeiro cultivar 'Rama Forte' com seis anos de idade, formada por 33 plantas espaçadas em 5 x $4 \mathrm{~m}$, pertencente ao Departamento de Produção Vegetal, Setor de Horticultura, da Escola Superior de Agricultura "Luiz de Queiroz" (ESALQ), em Piracicaba - SP. O município localiza-se a $546 \mathrm{~m}$ de altitude, $22^{\circ} 42^{\prime} 30^{\prime \prime}$ 'S e 47 $38^{\prime} 00^{\prime}$ " W. O clima da região é do tipo Cwa (Köppen, 1900), com temperatura média anual de $21,4{ }^{\circ} \mathrm{C}$ e chuvas concentradas de outubro a março, somando $1.257 \mathrm{~mm}$ anuais (Sentelhas \& Pereira, 2000). Os dados climatológicos foram coletados no Posto Meteorológico localizado na ESALQ.

A fenologia das plantas foi caracterizada pelos descritores de alongamento dos ramos, florescimento, desenvolvimento dos frutos e das folhas, e do abortamento natural de frutos, a partir da coleta semanal de frutos abortados, em onze plantas selecionadas ao acaso no pomar. Considerando o período em que as plantas manifestavam cada um desses eventos, foram definidas as datas de início e fim de cada estádio fenológico.

A amostragem de ramos e raízes para a análise dos teores de carboidratos foi conduzida por 12 meses consecutivos, de setembro/2002 a agosto/2003. A fim de evitar a remoção contínua de ramos e de raízes sempre das mesmas plantas, foi estabelecido um sistema de rodízio entre 12 grupos de sete plantas. Para tanto, as 33 plantas do pomar foram subdivididas em grupos de sete plantas (seleção aleatória) até formarem 12 diferentes grupos.

Sempre no $15^{\circ}$ dia de cada mês, pela manhã, três ramos produtivos localizados na periferia e altura mediana da copa de cada uma das sete plantas e com o mesmo número de frutos eram coletados, tendo seus frutos e folhas removidos e descartados. Sob a projeção da copa dessas mesmas plantas, segmentos de raízes, com cerca de $20 \mathrm{~cm}$ de comprimento e $1 \mathrm{~cm}$ de diâmetro, eram removidos, eliminando-se o solo aderido.

Após a coleta, as amostras de raízes e ramos eram congeladas em freezer por $48 \mathrm{~h}$ para minimizar a ação de enzimas endógenas (Cecato et al., 2001). Em seguida, o material era desidratado por $72 \mathrm{~h}$ em estufa ventilada a $80^{\circ} \mathrm{C}$ e moído a $1 \mathrm{~mm}$ de espessura, sendo, posteriormente, encaminhado para a análise dos teores de amido e de carboidratos solúveis totais (CST).

Para a análise do amido, foi utilizada a técnica de espectrofotometria de refletância no infravermelho proximal NIRS (Pires \& Prates, 1998). As amostras secas e moídas foram escaneadas, sendo coletados os espectros NIRS na faixa de 1.100 a $2.498 \mathrm{~nm}$, utilizando-se do equipamento modelo NIRS 5000 (NIRSystem, Silver Spring, MD, USA) acoplado ao computador equipado com o software Win ISI II versão 6,2 (Intrasoft International, PA).

Para a análise dos carboidratos solúveis totais (CST), foi empregado o método do ácido sulfúrico concentrado, descrito em Dubois et al. (1956). Para a extração, $100 \mathrm{mg}$ da amostra seca e moída foi acrescida de $100 \mathrm{~mL}$ de solução de etanol (80\%) e colocada em banho-maria a $80^{\circ} \mathrm{C}$, por 30 minutos. Posteriormente, o material foi filtrado, e o resíduo sólido descartado, completandose o volume para $500 \mathrm{~mL}$ com água destilada. Em seguida, foram retiradas alíquotas de $2 \mathrm{~mL}$ do extrato etanólico, adicionando-se $1 \mathrm{~mL}$ de solução de fenol $5 \%$ e $5 \mathrm{~mL}$ de ácido sulfúrico concentrado. Foi construída uma curva-padrão com concentrações crescentes de solução de glicose a 0,01\%, conduzindo-se as leituras das amostras em espectrofotômetro a $510 \mathrm{~nm}$ de absorbância. Os teores de CST foram calculados em mg x $100 \mathrm{~mL}^{-1}$,em $100 \%$ de matéria seca, sendo que o material apresentou média de $98,8 \%$ de matéria seca.

O delineamento experimental foi inteiramente casualizado, com sete repetições, sendo a análise estatística dos teores de amido e de CST realizada separadamente para raízes e ramos. Para a análise dos dados, foi empregado o programa SISVAR para Windows versão 4.0 (Ferreira, 2000).

\section{RESULTADOS E DISCUSSÃO}

O alongamento dos ramos do caquizeiro foi iniciado em 06 de setembro de 2002. A análise de variância mostrou a 
existência de diferenças significativas $(\mathrm{P}<0,05)$ nos teores de amido e de carboidratos solúveis totais (CST), nos ramos (Figura 1) e nas raízes (Figura 2), entre os diferentes estádios fenológicos do caquizeiro variedade Rama Forte.

\section{Variação de carboidratos nos ramos}

Semelhantemente aos resultados obtidos por George et al. (1994a) com caquizeiro 'Fuyu', no período compreendido entre o alongamento dos ramos e o florescimento (Figura 1), foi registrada queda significativa no teor de amido nos ramos, ao mesmo tempo em que se registrou aumento significativo nos teores de CST. Esses resultados evidenciam que, para o início de um novo ciclo da cultivar Rama Forte, foi necessária a mobilização das reservas do amido contido nos ramos.

Concluída a antese, foram registrados dois picos no abortamento de frutos: o primeiro em 29-10 e o segundo em 0612. Iniciado o amadurecimento dos frutos remanescentes, a partir de fevereiro, foram observadas as primeiras folhas em senescência. A partir dessa fase, ocorreu um aumento progressivo no acúmulo de amido nos ramos (Figura 1), até o início da fase de abscisão foliar. Esses resultados coincidem com o relato de George et al. (1994b), ao mencionarem que a reposição no estoque de amido, em órgãos lenhosos de caquizeiro 'Fuyu', somente ocorreu após o florescimento e o término do abortamento de frutos. Darnell e Birkhold (1996) citam que, em cerejeira, essa reposição teve início somente a partir da colheita dos frutos. Yoshioka et al. (1988), ao obterem resultados semelhantes trabalhando com macieira, justificam que, a partir do florescimento, os carboidratos fotossintetizados na estação corrente passaram a suprir não só o desenvolvimento dos frutos e a respiração da planta, como também a reposição dos tecidos armazenadores de reservas. Assim, o aumento significativo nos teores de amido observado entre janeiro e abril (Figura 1) pode ser explicado por mudanças nas relações fonte-dreno na planta, estimulada pela estabilização da carga definitiva de frutos. Os fotoassimilados, ora destinados à carga inicial de frutos, teriam sido, então, redirecionados a outros drenos, no caso presente, os tecidos de reserva localizados nos ramos. Na fase de précolheita dos frutos, Collins \& George (1996) registraram teores de $8 \%$ de amido nos ramos e de $10 \%$ nas raízes do caquizeiro 'Fuyu' cultivado na Austrália. No presente estudo, os teores de amido registrados para essa mesma época (entre fevereiro e março/2003) foram de $13,7 \%$ para os ramos e $11,8 \%$ para as raízes. Iniciada a abscisão foliar em abril, sob temperatura mínima de $11,5^{\circ} \mathrm{C}$ (Figura 3), ocorreu nova mobilização de amido em CST nos ramos (Figura 1). Ao obter resultado semelhante em estudo realizado com macieira, Yoshioka et al. (1988) justificam essa mobilização como um mecanismo de resistência ao frio, cuja finalidade é garantir o provimento de energia e de substratos para o crescimento inicial dos ramos na primavera subseqüente.

\section{Variação de carboidratos nas raízes}

Entre os meses de setembro e outubro, período compreendido entre o alongamento dos ramos e o florescimento, ocorreu queda significativa no teor de amido sem, contudo, ter ocorrido o correspondente aumento em CST nas raízes (Figura 2). Esse fato sugere que os ramos, por disporem de um suprimento suficiente em reservas, foram menos dependentes daquela proveniente de órgãos mais distantes durante o alongamento dos ramos. Darnell \& Birkhold (1996) citam estudos mostrando que as reservas contidas em ramos de cereja e mirtilo também foram consumidas em detrimento daquela contida nas raízes durante o alongamento dos ramos. George et al.(1994a) registraram, para raízes do caquizeiro 'Fuyu' cultivado na Austrália, teores de amido superiores em relação aos ramos. No presente estudo, contudo, a concentração média de amido foi de $10 \%$ para raiz e de $11 \%$ para os ramos.

Iniciado o amadurecimento dos frutos (fevereiro), ocorreu aumento progressivo do acúmulo de amido nas raízes (Figura 2). A partir da abscisão foliar, ocorreu queda significativa nos teores de amido nas raízes, apesar de os dados não caracterizarem sua mobilização para CST. Em julho, com as plantas já totalmente desfolhadas, o teor de amido nas raízes teve um súbito aumento (Figura 2).

Nas raízes, a variação dos teores de amido foi mais significativa em relação àquela verificada para o CST. Esse fato sugere um controle metabólico rigoroso, no sentido de evitar a ocorrência de variações bruscas na disponibilidade de CST nesses órgãos, às custas da mobilização do amido (efeito tampão).

O presente estudo comprova a existência de variações significativas nos teores de CST e amido para a variedade Rama Forte cultivada em clima tropical. A partir desses resultados, novos estudos poderão ser conduzidos com o objetivo de melhor compreender as relações fonte-dreno na planta, verificando, por exemplo, como a variação nos teores desses carboidratos responderá a diferentes sistemas de manejo, como épocas ou intensidades de poda ou raleio de frutos, entre outras práticas.

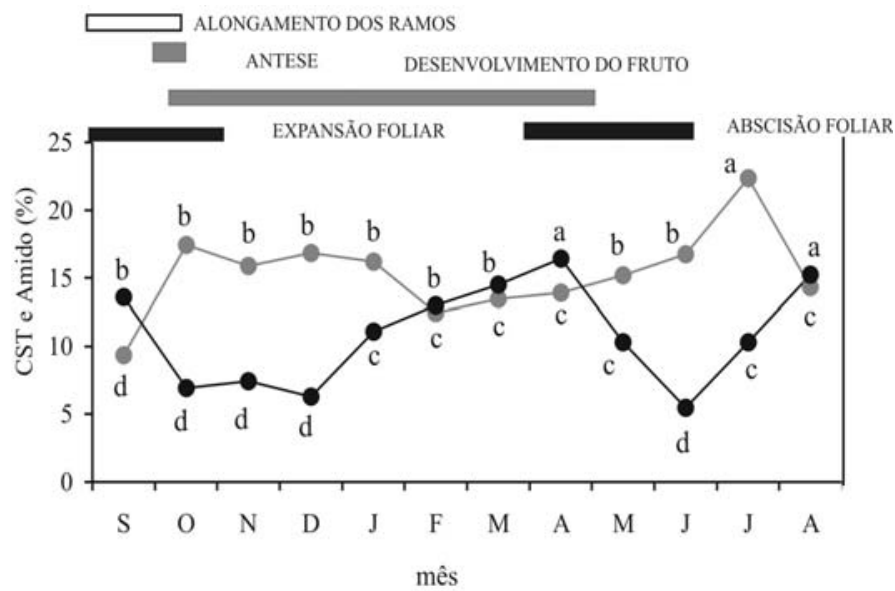

FIGURA 1 - Variação mensal dos teores de amido (- - ) e de carboidratos solúveis totais -CST ( - - $)$ em ramos do caquizeiro 'Rama Forte', no período de setembro/2002 a agosto/2003, em Piracicaba - SP. Médias seguidas de mesma letra para cada carboidrato analisado não diferem estatisticamente, pelo teste Scoot-Knott $(\mathrm{P}<0,05)$. A ocorrência e a duração dos estádios fenológicos estão nas barras horizontais. 


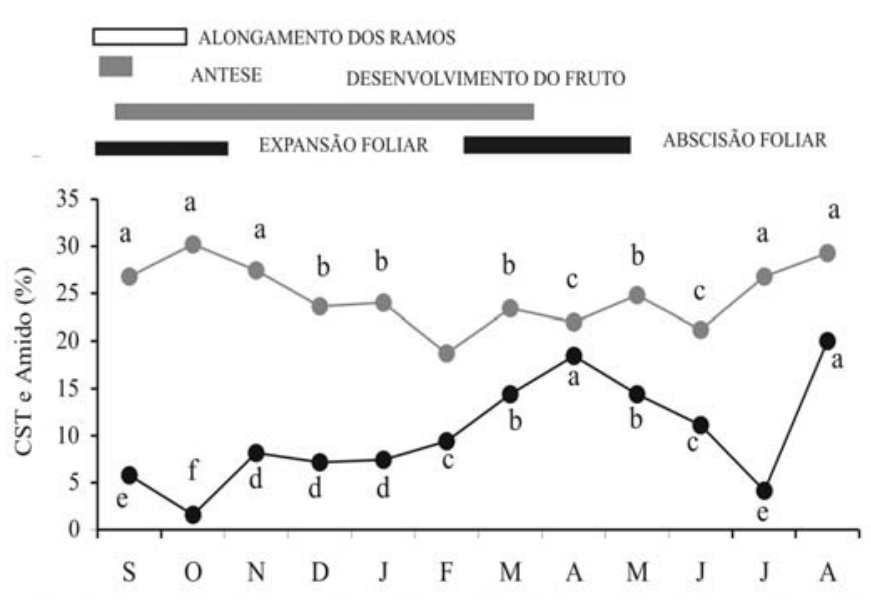

FIGURA 2 - Variação mensal dos teores de amido (-) e de carboidratos solúveis totais - CST (-๑) em raízes do caquizeiro 'Rama Forte', no período de setembro/ 2002 a agosto/2003, em Piracicaba - SP. Médias seguidas de mesma letra para cada carboidrato analisado não diferem estatisticamente, pelo teste Scoot-Knott $(\mathrm{P}<0,05)$. A ocorrência e a duração dos estádios fenológicos estão nas barras horizontais.

\section{CONCLUSÕES}

1-A mobilização do amido de reserva nos ramos de caquizeiro cultivar Rama Forte teve grande importância na sustentação de um novo fluxo de brotações no início do desenvolvimento vegetativo.

2-A abscisão foliar, é caracterizada por um novo período de consumo de amido, tanto nas raízes como nos ramos.

3-A reposição no estoque de amido de reserva nos ramos e nas raízes ocorre, principalmente, entre o florescimento e a abscisão foliar.

4-A mobilização do amido foi mais significativa nas raízes do que nos ramos do caquizeiro Rama Forte.

\section{AGRADECIMENTOS}

À Fundação de Amparo à Pesquisa para o Estado de Minas Gerais - FAPEMIG, pela bolsa de estudos concedida ao primeiro autor, e ao Professor Luiz Gustavo Nussio, do Departamento de Zootecnia da ESALQ/USP, pelas análises de amido.

\section{REFERÊNCIAS}

Rodrigues, AC.; Herter, F.G.; Veríssimo, V.; Campos, A.D.; Leite, G.B. SATO, G.S.; ASSUMPÇÃO, R. Mapeamento e análise da produção do caqui no Estado de São Paulo. Informações Econômicas, São Paulo, v.32, n.6, p.47-54, 2002.

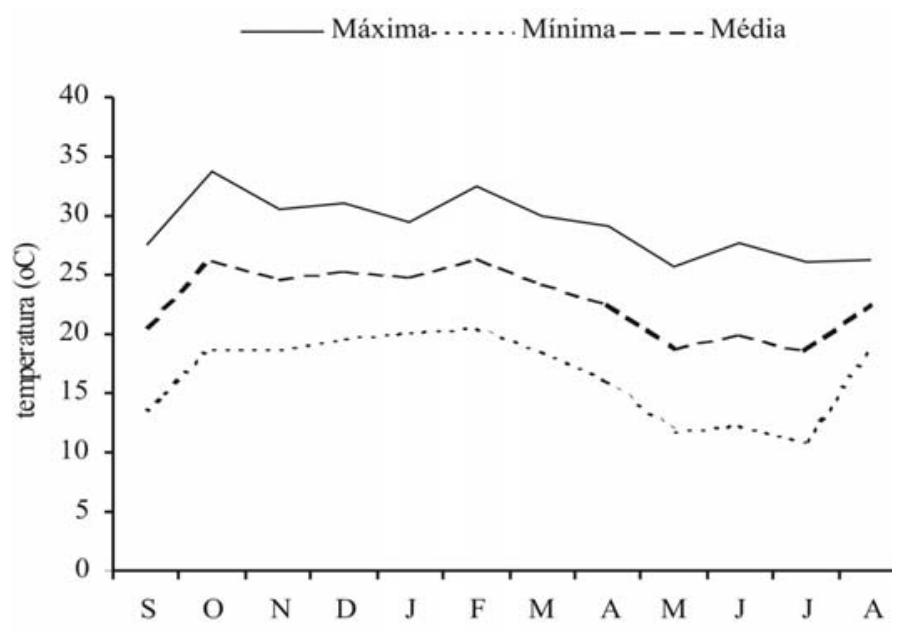

FIGURA 3 - Variação mensal da temperatura em Piracicaba SP, no período de setembro/2002 a agosto/2003.

CARVALHO, R.I.N.; ZANETTE, F. Conteúdo de carboidratos em gemas e ramos de macieira durante o outono e inverno em região de baixa ocorrência de frio. Revista Brasileira de Fruticultura, Jaboticabal, v.26, n.2, p.202-205, 2004.

CECATO, U.; CANO, C.C.P.; BORTOLO, M.; HERLING, V.R.; CANTO, M.W.; CASTRO, C.R.C. Teores de carboidratos não estruturais, nitrogênio total e peso de raízes em coastcross-1 (Cynodon dactylon L. Pers) pastejado por ovinos. Revista Brasileira de Zootecnia, Viçosa, v.30, n. 3, p.644-650, 2001.

COLLINS, R.J.; GEORGE, A.P. Managing crop load on nonastringent persimmon (Diospyros kaki L. ) grown in the subtropics. Acta Horticulturae, Leuven, n.436, p.251-260, 1996.

CORSATO, C.E; SCARPARE FILHO, J.A.; VERDIAL, M.F. Fenologia do caquizeiro Rama forte em clima tropical. Bragantia, Campinas, v.65, n 3, p.323-329, 2005.

DARNELL, R.L.; BIRKHOLD, K.B. Carboydrate contribution to fruit development in two phenologically distinct rabbiteye blueberry cultivars. Journal of the American Society for Horticultural Science, Alexandria, v.121, n.6, p.1132-1136, 1996.

DUBOIS, M.; GILES, K. A.; HAMILTON, J.K. Colorimetric method for determination of sugars and related substances. Analytical Chemistry, Washington, v.28, p.350-356, 1956. 
FERREIRA, D.F. Análises estatísticas por meio do Sisvar para Windows versão 4.0. In REUNIÃO ANUAL DA REGIÃO BRASILEIRA DA SOCIEDADE INTERNACIONAL DE BIOMETRIA, 45., 2000, São Carlos: UFSCAR, 2000. p.255-258.

GEORGE, A.P., COLLINS, R.J.; RASMUSSEN, T.S. Phenological cycling of non-astringent persimmon in subtropical Australia. Journal of Horticultural Science, Bangor, v.69, n.5, p.937-946, 1994a.

GEORGE, A.P.; NISSEN, R.J.; COLLINS, R.J. Effects of temperature and pollination on growth, flowering and fruit set of the non-astringent persimmon cultivar Fuyu under controlled temperatures. Jounal of Horticultural Science, Bangor, v.69, n.2,p.225-230, 1994b.

HERTER, F.G.; VERÍSSIMO, V.; CAMELATTO, D., GARDIN, J.P.; TREVISAN, R. Abortamento de gemas florais de pereira no Brasil. In: SEMINÁRIO DE FRUTICULTURADECLIMATEMPERADO NO BRASIL, 1., 2001, Florianópolis. Anais... p.106-114.

LARCHER, W. O balanço de carbono nas plantas. In: LARCHER, W. Ecofisiologia vegetal. São Carlos: Rima, 2000. p. 69-182:

LIU, X.; ROBINSON, P.W.; MADORE, M.A.; WITNEY, G.W.; ARPAIA, M.L. Hass avocado carbohydrate flutuations. I. Growth and phenology. Journal of the American Society for Horticultural Science, Alexandria, v.124, n.6, p.671-675, 1999.

MOWAT, A.D.; GEORGE, A.P. Persimmon. In: Schaffer, B.; Andersen, P.C. Handbook of environmental physiology of fruit crops: temperate crops. Boca Raton: CRC Press, 1994. v. 1, p.209232.
MOWAT, A.D.; GEORGE, A.P., COLLINS, R.J. Cultivation of persimmon (Diospyros kaki L.) under tropical conditions Acta Horticulturae, Leuven, v.409, p.141-149, 1995.

PIRES, F.F.; PRATES, E.R Uso da técnica da espectrofotometria de reflectância no infravermelho proximal (NIRS) na predição da composição química da alfafa (Medicago sativa, L.). Revista Brasileira de Zootecnia, Viçosa, v.27, p.1076-1081, 1998.

RODRIGUES, A C.; HERTER, F.G.; VERÍSSIMO, V.; CAMPOS, A.D.; LEITE, G.B. SATO, G.S.; ASSUMPÇÃO, R. Mapeamento e análise da produção do caqui no Estado de São Paulo. Informações Econômicas, São Paulo, v.32, n.6, p.47-54, 2002.

SENTELHAS, P.C.; PEREIRA, A.R. A maior estiagem do século? Notícias Piracena, Piracicaba, v.6. n.50, p.1, 2000.

SMITH, M.W.; MACNEW, R.W.; AGER, P.L.; COTTEN, B.C. Seasonal changes in the carbohidrate concentration in pecan shoots and their relationship to flowering. Journal of the American Society for Horticultural Science, Alexandria, v.11, n.4, p.558-561, 1986.

VANTINI, P.P; RODRIGUES, T.J.D.; CRUZ, M.C.P.; RODRIGUES, L.R.A.; MALHEIROS, E.B. Teores de carboidratos nãoestruturais do capim Tanzânia adubado com diferentes doses de nitrogênio. Acta Scientiarum Animal Sciences, Maringá, v 27, n. 4, p.425-432, 2005 .

WARDLAW, I.F. The control of carbon partitioning in plants. New Phytologist, Lancaster, v.116, p.341-381, 1990

YOSHIOKA, H., NAGAI, K., AOBA, K., FUKUMOTO, M. Seasonal changes of carbohydrates metabolism in apple trees. Scientia Horticulturae, Amsterdan, v.36, p.219-227, 1988. 